\title{
CASE REPORT: UNUSUAL PRESENTATION OF PHAEOCHROMOCYTOMA
}

\author{
E El-Kady, J Brigg, F Christian, S Spooner \\ Department of Surgery, Lancaster Acute Hospitals Trust
}

\section{INTRODUCTION}

Pheochromocytoma, a term introduced by Pick in $1912^{(1)}$, denotes a Chromaffin Cell Tumour. It arises within the adrenal medulla or within the sympathetic nervous system ${ }^{(2)}$. Extra-adrenal pheochromocytoma therefore may arise in any portion of paraganglion system. The most common extraadrenal site is the superior para-aortic region between diaphragm and lower renal poles ${ }^{(3)}$.

Pheochromocytoma is classically associated with paroxysms of headache and hypertension. Its presentation, however, may be varied and subtle ${ }^{(4)}$ as the following case report will show.

\section{CASE REPORT}

A 48-year-old man has been operated upon twice for pheochromocytoma and each time, the clinical presentation was unusual and "atypical".

\section{First presentation}

Twenty-five years ago he had presented with a "twisted" right thumb. On routine general examination at the time, BP was $260: 170 \mathrm{mmHg}$, so attention was directed away from his thumb to his high blood pressure. Left adrenal pheochromocytoma was diagnosed by aortogram and high levels of catecholamines in 24 hours urine. He was subjected to left adrenalectomy and splenectomy on 15.4.71.

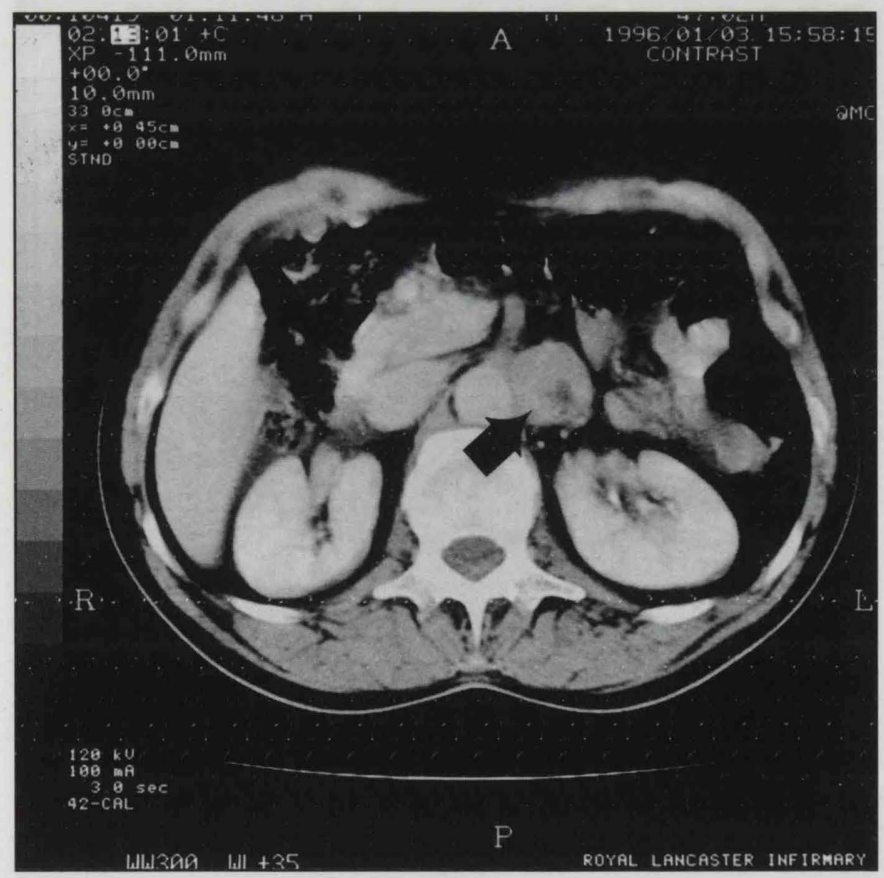

Figure 1
Histological examination showed a classical pheochromocytoma with no cytological evidence of malignancy.

Follow-up by urine metadrenaline assay showed normal levels for 15 years after the operation.

\section{Second presentation}

Four years ago the patient suffered from many episodes of left upper quadrant and flank abdominal pain, which needed two hospital admissions. Abdominal clinical examination was consistently negative and BP normal. Urine metadrenaline was within normal range (below 5.5 umol per 24 hours urine).

Computed tomography (CT), however, showed a retroperitoneal mass (Figure 1), suggesting recurrence of the pheochromocytoma. As the pictures indicate, this mass was closely applied to the abdominal anorta, anterolateral to the vertebral body (arrow).

On laparotomy, the tumour lay between the abdominal aorta and the hilum of the left kidney, with the left renal vein stretched over it.

The tumour was grey in colour, firm in consistency, well demarcated and capsulated (Figure 2), with large vessels in the immediate vicinity of the tumour, and the tumour itself served by an abundant tumour circulation. Dissection had to be meticulous. The tumour was removed in toto and clearance was complete macroscopically and histologically.

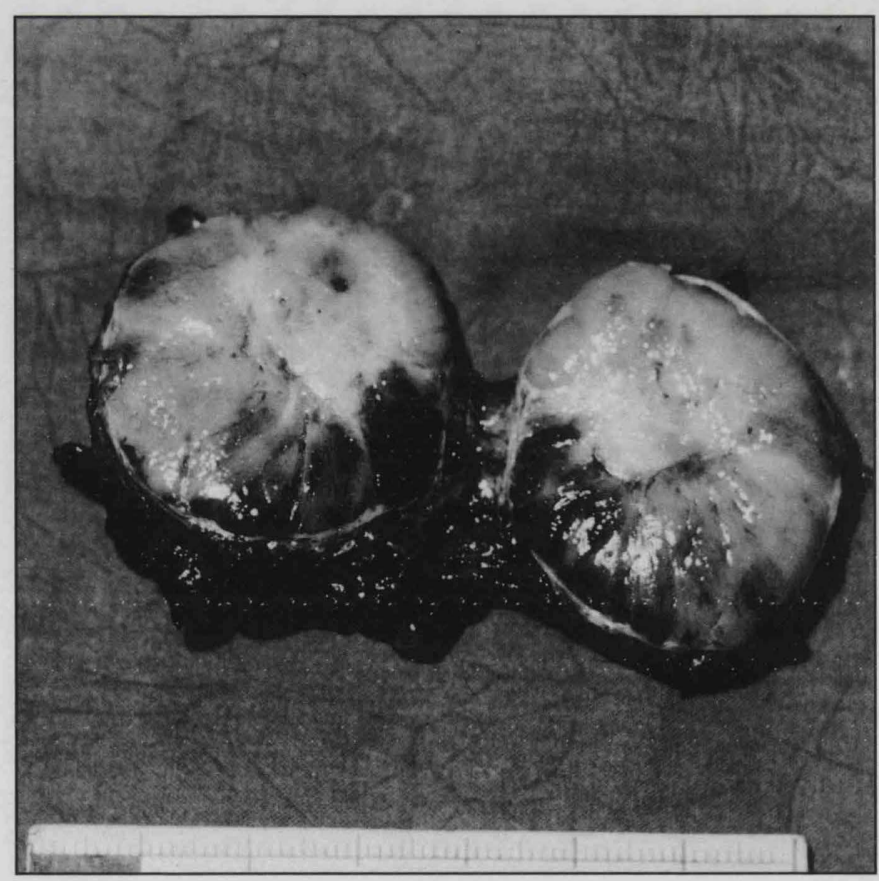

Figure 2 
Histological examination showed classic pheochromocytoma. The previous sections from the lesion removed in 1971 had been reviewed and the appearances were very similar to those in the present resection specimen.

\section{DISCUSSION}

Although traditional teaching has been that $10 \%$ of all pheochromocytoma are at extradrenal sites, this may be underestimated. It has been reported that extra-adrenal pheochromocytoma probably represent at least $15 \%$ of adult pheochromocytoma. $^{(4)}$

In the patient described, the anatomical site and microscopic appearance of autonomic ganglia surrounding the tumour, proved that the lumbar sympathetic chain was the source of this extra-adrenal pheochromocytoma.

The experience with this patient supports the view that extra-adrenal pheochromocytoma can develop spontaneously and asymptomatically, many years after removal of the same side adrenal gland for pheochromocytoma.

\section{REFERENCES}

1 Burnand KG, Young AE In: The New Aird's Companion in Surgical Studies Churchill Livingstone 1992122630

2 Agana Defensor R, Proch M Pheochromocytoma: a clinical review AACN Clinical Issues in Critical Care Nursing 1992;3(2):309-318

3 Whalen RK, Althausen AF Extra-adrenal phaeochromocytoma (review) J Urol 1992;147(1):1-10

4 Counselman FL, Brenner CJ Adrenal phaeochromocytoma with persisting abdominal and flank pain (review) J Emerg Med 1991;9(4):241-246

\section{Answers to quiz on page 311}

1. Oncogenes code for proteins which cause cell division to be switched on. These genes are normally inactive in quiescent cells but in theory the activation of a single oncogene can lead to uncontrolled cell division and neoplasia.

2. Anti-oncogenes code for proteins which suppress cell division. Thus neoplasia can only occur if both antioncogenes of an allelic pair are rendered inactive by mutation.

3. In retinoblastoma the tumour arises when both anti-oncogenes of an allelic pair (retinoblastoma genes) are inactivated by mutation in one of the cells in the developing retina. In hereditary retinoblastoma the child inherits one inactive retinoblastoma gene from one of its parents. The chance of the second retinoblastoma gene undergoing mutation is approximately 1 in $1,000,000$ per cell division, but since there are more than $1,000,000$ cell divisions in retinal cells this almost always occurs. In fact it occurs on average three times in each child leading to three tumours and a high chance of bilateral disease.

4. In children whose constitutional cells have two functioning retinoblastoma genes there is a good chance that one of the genes will undergo mutation in some cells during retinal development. But the chance of the second gene undergoing mutation in the same cell is remote. Thus sporadic retinoblastoma is rare and in practice there is never more than one tumour per individual. Thus the condition is always unilateral.

5. Hereditary retinoblastoma is both dominant and recessive. The pattern of inheritance is dominant in that a single mutant gene passed from parent to child leads to the disease. But each individual tumour requires the presence of two mutant retinoblastoma genes. A single mutant gene has no effect and is therefore recessive. 